\title{
Identifying the Factors That Affect the Success of Self-Efficiency and Self-Employment Plans among the Clients of Imam Khomeini's Relief Committee through the Lens of Social Entrepreneurship
}

\author{
Mohammad Hassan Mobaraki ${ }^{1}$, Alireza Mohageri ${ }^{1} \&$ Yadollah Karami ${ }^{1}$ \\ ${ }^{1}$ Faculty of Entrepreneurship, University of Tehran, Tehran, Iran \\ Correspondence: Yadollah Karami, Faculty of Entrepreneurship, University of Tehran, Tehran, Iran. E-mail: \\ y_k1350@yahoo.com
}

Received: November 6, 2011

Accepted: April 29, 2012

Published: June 1, 2012

doi:10.5539/ijbm.v7n11p43

URL: http://dx.doi.org/10.5539/ijbm.v7n11p43

\begin{abstract}
This study is intended to examine the relationship between the structural, environmental, and behavioral factors with the success rate of Imam Khomeini Relief Committee's self-sufficiency and self-employment plans through taking a social entrepreneurship approach. Our sample comprised of 152 clients and 12 social workers who were affiliated to the abovementioned committee. As the methodology of our study, mixed method was adopted, in that we studied the clients quantitatively through correlation regression and path analysis. On the other hand, the social workers were treated qualitatively and though underlying theory. After analyzing the quantitative data, the structural, environmental, and behavioral factors were found to be the predicators of success rate of these occupational plans. In the examined structural, environmental, and behavioral factor, therefore, capital and employment, regulations and incentives, innovation and identifying the opportunities were meaningful, respectively. There also happened to be a correlation between our structural and behavioral factors. In analyzing the research's qualitative data, then, these three factors were of considerable significance. In sum, the highest rates of significance in these factors were as following: capital, employment, and communication system in the structural factors; regulations and incentives in the environmental factors; and training, innovation, and risk-taking in the behavioral factors.
\end{abstract}

Keywords: Imam Khomeini's relief committee, indicators of success, behavioral factors, environmental factors, structural factors, three-dimensional model, self-sufficiency and self-employment plans

\section{Introduction}

The evolving field of social entrepreneurship is increasingly growing and continues to capture the interest and imagination of scholars, researchers, and practitioners alike. The term "social entrepreneurship" reminds us of the great missions of the well-known social organizations such as Ashoka, Showab, Skoll, and Imam Khomeini's Relief Committee in Iran, among others. Social entrepreneurship is not a novel phenomenon as it has been around from the moment social institutes have been established. What distinguishes social entrepreneurship from other types of entrepreneurship (e.g., economic and organizational) is the preference of social interests in this field. Though identifying those poor people who are not capable of establishing a business by their own, the social entrepreneurship organizations try to empowerment them to heighten their living standards, and in doing so, such organizations have contributed to realize high social missions such as justice, removing discriminations, and eradicating poverty. Innovation and laying emphasis on social entrepreneurship have been argued to be essential in bringing sustainable welfare and health to society. (Mohajeri, 2008:20) Although social entrepreneurship has a long history in economic and trade risk-taking, nowadays it is increasingly adopted in solving the social problems. (Emerson and Twersky, 1996:42)

Donations and charity can contemporarily promote the living standards of the poor and increase their potentials to access education, health care, sanitary, non-discriminatory environment, and food items. However, these practices neither uproot poverty, nor decrease the stressful situation of the poor forever. Of course charity and donation is critical in eliminating the ugly signs of poverty, but it cannot provide the poor with sustainable self-employment and self-efficiency. And sometimes they may even be harmful to the needy people. Mohammad 
Yeunos, the founder of Geramin Bank and a forerunner in establishing macro-level economic institutes, who won the 2006 Noble Prize, observes that once we want to help the poor, we often try to give them donation and charity. Giving charity has become a way to ignore diagnosis and finding an effective solution for the chronic situation of the poor. To Yeunos, therefore, charity is not a crucial solution for such needy people. As he has well put it, charity has proven to be a means to disarm the poor with initiative, and as a result, it leads to the perpetuation of poverty. Upon donating our charity, we are left with a safe conscience, and live our life without further preoccupation on the situation of the poor. Initiatives such as promoting the facilities of the schools or establishing new health care centers can increase the opportunities of the needy people to contribute to the economic activities in a more efficient way. However, it stands to reason that merely providing education and health care can no longer assure economic development or having access to employment, as those qualified, educated, health individuals who are not endowed with capital, state-of-the-art technologies, free markets, and business literacy will encounter innumerable difficulties in putting their competences into practice. The poor, however, are in urgent need of some appropriate credit and financial resources to enjoy their in hand potentials in the best possible way, and as a result promote their living standards and efficiency. (Gregory, 2007:4)

The public, non-profit institutes which have supporting the vulnerable masses and classes of society as their main mission, play a crucial role in mobilizing, supporting, and even funding the beneficial economic initiative aimed at strengthening the situation of the poor. This argument that social entrepreneurship is an organization which integrates the passions of a social mission with the notions of business and trade (Certo and Miller, 2008:270) gives us more enthusiasm to investigate those institutes which have been devoted to social entrepreneurship. Being established in 1979 as a public institute to assist the poor and oppressed individuals of society and paving the ways for their self-efficiency, Imam Khomeini's Relief Committee has not merely served as a social service institute. Instead, this committee has assumed responsibilities in areas as diverse as: building equal opportunities for the poor, empowering the oppressed people to become self-reliant, strengthening their self-esteem, promoting the social relationships, decreasing the socio-cultural problems, making the facilities more available, satisfying the basic needs of the poor, and encouraging the public participations. This committee has an ever-increasing body of support-seekers under its support umbrella. In Kurdistan province, for example, it has been reported that some 56515 poor families (141900 people) has enjoyed the supports of this committee in 2008. Broadly speaking, this committee has mainly been active in gathering the public donations and distributing these funds and materials among its needy subsistent. (Statistical Yearbook of Imam Khomeini's Relief Committee, 2008:86)

Principal among this committee's initiatives to encouraging self-employment and creating job for the poor are the self-sufficiency and self-employment plants which attract an increasing body of the applicants. This employment and self-sufficiency division of this committee has always sought to: 1) promoting the level of cultural, academic, vocational, and technical competence of its subsistent; 2) increasing the economic ability of the poor to the extent that they get self-sufficient and they no longer suffer from the chronic signs of poverty in their individual and familial life; and, 3) cultivating the culture of entrepreneurship and hard working among the poor to encourage them in their search for the better life. (Statistical Yearbook of Imam Khomeini's Relief Committee, 2008:145)In fact, the mission of this committee is two-fold: from one hand, it seeks to create job for the poor and making grounds for their subsistence, and on the other hand, it tries to provide them with training various vocations and skills, in order for them to be empowered and independent from the further financial supports of this committee. With regard to this fact that each year this committee allocates a considerable budget to job-creation and job-finding plans and training for its subsistent, it seems justifiable to conduct a study on the success rates of such plans. The development of such plans has by now proven to be of a considerable importance in empowering those who have enjoyed these plans. However, at one hand, conducting such plans is extremely costly, and on the other hand, it is observe that the number of the families receiving support from this committee is growing; so, conducting these plans by putting the crucial factors of success into consideration and decreasing the time needed for a family to become self-sufficient can both decrease the financial pressure of such plans and provide these supports for a greater number of the poor families. In this study, therefore, it is intended to examine the relationship between the structural, underlying, and behavioral factors with the success rate of Kurdistan province's Imam Khomeini Relief Committee's self-sufficiency and self-employment plans through taking a social entrepreneurship approach. The findings of this study will give the authorities of this committee insight into making more appropriate policies for increasing their future self-employment plans.

\section{Research Questions}

\subsection{The Main Question}

(i) What are the elements that influence the success rate of the self-sufficiency and self-employment plans of 
Imam Khomeini Relief Committee through the lens of social entrepreneurship?

\subsection{Secondary Questions}

1) If the structural factors influence the success rate of the self-sufficiency and self-employment plans of Imam Khomeini Relief Committee?

2) If the behavioral factors influence the success rate of the self-sufficiency and self-employment plans of Imam Khomeini Relief Committee?

3) If the underlying (environmental) factors influence the success rate of the self-sufficiency and self-employment plans of Imam Khomeini Relief Committee?

4) To what extent does each one of the above-mentioned factors contribute to the success rate of the self-sufficiency and self-employment plans of Imam Khomeini Relief Committee?

\section{Theoretical Framework and Literature Review}

\subsection{Definitions of Social Entrepreneurship}

The term "social entrepreneurship" has come to mean many things to many scholars. What follows is a review over the most prominent definitions that exist about this term.

Social entrepreneurship involves those non-profit organizations which assist the individuals in launching their own businesses and then applies their resources for the sake of social issues. (Moghimi, 2004:461)

Social entrepreneurship includes the development of the innovative plans that are aimed at promoting the lifestyle of those who are lacking in business and financial power or those who have difficulties in enjoying the opportunities of social services. (World Bank as cited in the Encyclopedia of Entrepreneurship, 2007: 460)

Social entrepreneur is someone who undertakes a non-profit business with the aim of generating income for public services. (Roger, 2006:402)

Social entrepreneurship is an organization which incorporates the passion of a social mission with the insights of business and trade (Certo and Miller, 2008:270)

Social entrepreneurship is a process through which the individuals, groups, and the social spheres take part voluntarily to make the best use of the inactive social possessions and identify their values. In such communities, however, the members seek to solve the social problems through mutual collaboration, to build and develop a trust-based stock of social capital, and direct the potential energy of this capital to develop a stable source for solving their problems. (Leadbeater.C, 2002: 3)

Social entrepreneurship is either the application of an entrepreneurial behavior in achieving the social goods, as opposed the personal interests, or and an institute which provides some benefits for the deprived masses of society. (Hilbert et al, 2000: 77)

\subsection{Types of Social Entrepreneurship}

Social entrepreneurship is of three types:

1) Integrated social entrepreneurship: any economic activity that is clearly designed based on the social needs and values to generate positive social achievements can be classified in this group;

2) Re-distributive social entrepreneurship: this type refers to any economic activity within the non-profit organizations and institutes that is intended to benefit from the available resources and competence to reduce the costs, to increase the incomes, and to diversify the costs and incomes.

3) Supplementary social entrepreneurship: whenever a non-profit organization or institute engages in establishing a new division for its own economic activities with the aim of covering its costs by the benefits of this new division, one can say that it has created supplementary social entrepreneurship.

\subsection{The History of Social Entrepreneurship}

Taking a glance over the literature on social entrepreneurship indicates that one should put two important things into account. First, the history of the development of socialentrepreneurship is barely a few decades. Second, social entrepreneurship should be regarded in terms of the social functions and the efforts made to solve the social problems, assisting and directing the deprived, excluded, and the vulnerable classes of society. The very idea of social institutes or the humanistic economic activities are rarely novel and have been in existence throughout the history of human societies; however, the term " social entrepreneurship" with its contemporary meaning has been at first introduced in the late 1990s in the American business sphere and gradually 
penetrated the academic circles. (Johnson et al, 2006: 1-4)

\subsection{The Contributions of the Institutes of Social Entrepreneurship to the Poor's Life}

Through four different ways, the institutes of social entrepreneurship which have been proven to be the supporters of the poor, contribute to the empowerment of the poor. These four ways being:

1) The poor as producers: in this procedure, however, the institute of social entrepreneurship appears as the provider of the appropriate technologies for the poor that can assist them in earning enough income.

2) The poor as consumer: in the cases that the poor are in need of consumptive needs, therefore, the institute of social entrepreneurship tries to satisfy those needs for them.

3) The poor as savers: in the event that the poor need saving money to engage in their desired businesses, the institute of social entrepreneurship responds this need.

4) The poor as borrowers: in this sense, the institute of social entrepreneurship plays the role of a mediator which relates the poor entrepreneurs to the owners of financial resources.

\subsection{A glimpse at Earlier Research}

Although several studies have by now been conducted to evaluate the factors which contribute to the achievement of the self-sufficiency and self-employment plans ran by Imam Khomeini Relief Committee, there is next to no study to approach this area through a social entrepreneurship view. What follows, therefore, takes us straightly to the heart of the earlier scholarship on this subject.

- Zolfaghari(2003) has studied the success rate of the self-sufficiency and self-employment plans ran by the Semnan province's Imam Khomeini Relief Committee and suggested some practical recommendation which have the potential on making difference in the status qua of such plans. His study population consists of all the poor households of the province who have been engaged in the self-sufficiency and self-employment plans of this committee. By adopting Cochran Formula and systematic sampling methods, he has selected 1550 clients of this committee as his sample. His data collection tools, on the other hand, were field-work, post-occurrence, and questionnaire methods. The collected data, therefore, were analyzed through descriptive values of frequency, frequency percentage, and t-test. The findings of this study have shown the successful implementation of this committee's plans in different areas, including: establishing micro-level handicraft workhouses, rearing livestock, and training the clients.( The Human Force Deputy of Imam Khomeini Relief Committee, 2003)

- Karnama(2003) has studied the factors which have been proven as contributive to the achievement of the self-sufficiency and self-employment plans ran by Imam Khomeini Relief Committee in Kerman province. His research was survey and descriptive in nature, yet it can be regarded as a correlative study. His study population consisted of all the poor households which have benefited from the self-sufficiency and self-employment services provided by this committee since its establishment through 2002. By adopting the statistical formulas and in a random way, he has sampled some 267 clients. His data collection tool, however, was questionnaire. The findings reported that some 55/8 per cent of the administrators of the self-sufficiency and self-employment plans were female; some 76/5 per cent of the administrators indicated that the plans were appropriate to the competences and abilities of their households. In sum, just $6 / 6$ per cent of the whole implemented plans have achieved self-sufficiency and the remaining were stagnant, on-going, or closed.

- Tutunchi et al (1997) have investigated the achievements of the self-sufficiency and self-employment plans initiated by the Yazd province Imam Khomeini Relief Committee since 1989 to 1997. The study population comprised 1320 households which had been endowed with the different self-sufficiency services of this organization from 1983 to 1987 . Through taking a simple random sampling method, some 206 households were sampled. The study has been survey and descriptive in nature, and questionnaires were distributed and interviews were conducted to gather data. As demonstrated by the research's findings, the high number of family members and lack of appropriate expertise and skills among the clients positively contributed to the fail of these plans; however, other variables (e.g., differences in the price of the raw material, client's inability, and his/her inclination to apply for support from the committee) were far less that influential in the achievement of these plans.

- OmraniTabarestani (2009) has adopted the views of the social activists to identify and classify the factors which influence social entrepreneurship in Iran. Drawing on the conceptual model of Austin, this study has posed two questions in a hope to explore and classify the ideas of the social activists on the influential 
factors of achievement in the Iranian version of social entrepreneurship. The findings suggested that every five proposed factors of this conceptual model (i.e., individuals, mission, the environmental factors, opportunity, and capital, respectively) were considerably contributing to the development of social entrepreneurship in Iran.

- Weerawardena et al (2006) have adopted the base theory to develop a multi-dimensional model of social entrepreneurship. In their case study, therefore, they have introduced nine successful for-profit and non-profit organizations of social entrepreneurship. (p.32)

\subsection{Research Model}

The current study has applied the apparently reasonable three-dimensional model to evaluate the factors which contribute to the successful implementation of the self-sufficiency and self-employment plans ran by Imam Khomeini Relief Committee. This model, then, seeks to study the factors which influence a given phenomenon in terms of three dimensions of structure, environment, and behavior. The structural factors, however, include a set of regular relationships that prevail in the internal components of an organization, including: organizational structure, administrative relationships, capacity-building, capital, an effective communication system, and employment. The behavioral factors, also, include the human elements and relationships which shape the behavioral norms, informal relationships, and a certain set of correlated patterns. Furthermore, these behavioral factors are considered to be the dynamics of any organization, and elements such as leadership, innovation, creativity, and opportunity-seeking which are directly related to human force, can be included into this grouping. And finally, the environmental factors consist of the environment and the external conditions like extra-organizational sponsors, social incentives, and the regulations which develop the structural and behavioral factors. This model that has been developed through extracting the matrix of similar scholarship can be seen in Figure 1.

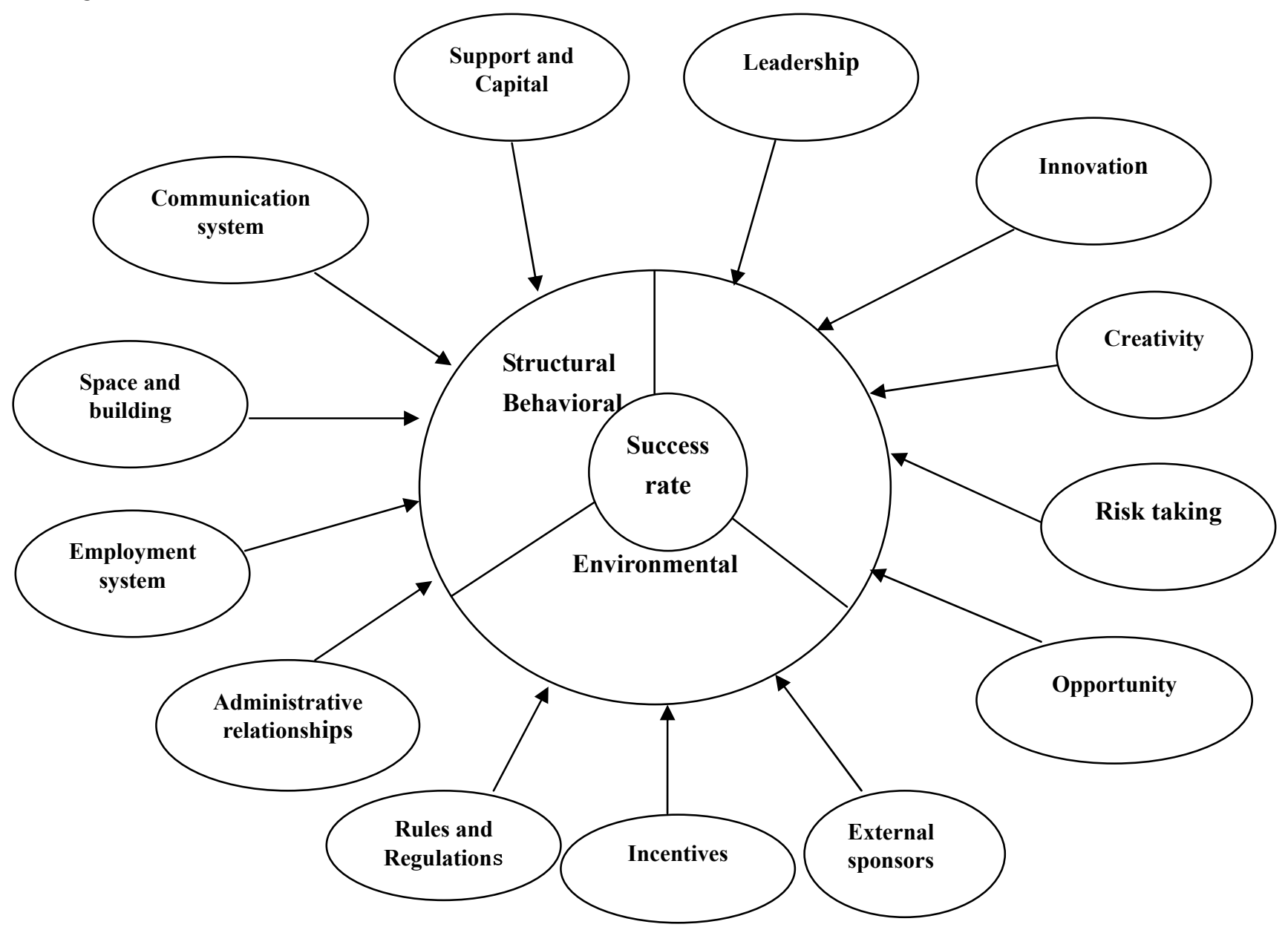

Figure 1. Research model based on the three-dimensional model (Mirzaee, 1997) 


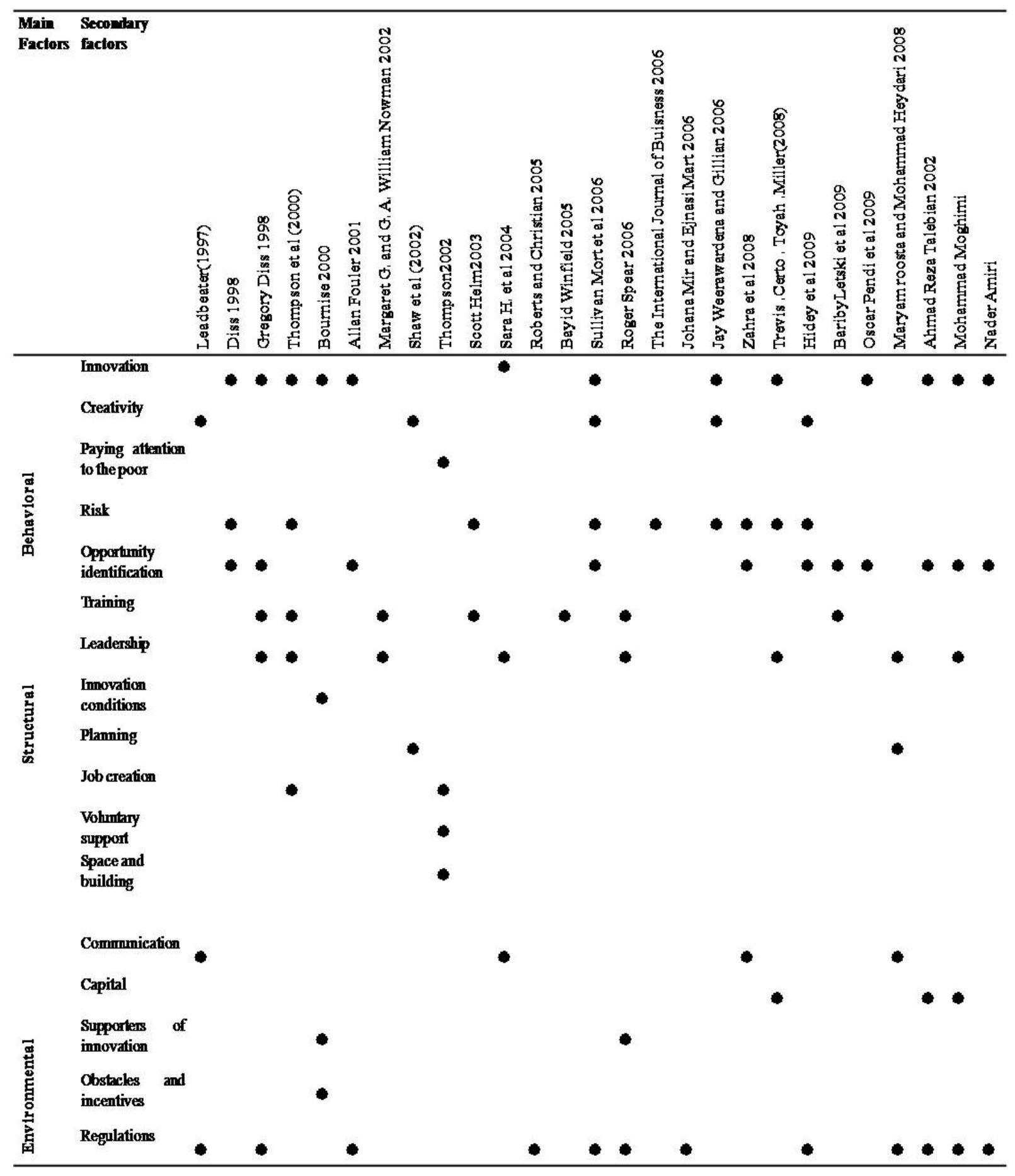

Figure 2. The matrix of the independent/dependent variables based on the prior researches

\section{Methodology}

Due to the multidimensionality of the social phenomena, no researcher can embark on investigating them through taking a mere qualitative or quantitative method, and the current research is no exempt from this rule. So, we have adopted a mixed method to examine our variables. Therefore, the present study has applied a qualitative grounded analysis which tries to explore the factors that according to the experts of Imam Khomeini Relief Committee, contribute to the achievement of the self-sufficiency and self-employment plans. The three-dimensional model of our key factors, however, was tested through a descriptive survey method. 


\subsection{Statistical Tests}

Our study has applied predictor correlation test to verify our variables. The correlative method is a descriptive method (non-experimental) which examines the simultaneity of two or more variables. This method is of three types: bivariate correlation, regression analysis, and the model of structural equations which is based on the analysis of covariance. (Soodmand et al, 2007: 91)

This study, therefore, seeks to predict the extent of the variations of our three latent variables (i.e., structural, behavioral, and environmental factors). This study has a regression analysis in which the effects of our predictive variables on the dependent variable (the success rate of the self-efficiency plans) are depicted by path analysis. Path analysis is argued to be an appropriate approach to test the conceptual model which extracts the direct or indirect relationships based on path coefficients. (Human, 2006:24)

\subsection{Data Collection Tools}

We developed an open interview to measure our qualitative variables, as the qualitative studies do not apt for testing a hypothesis, rather they try to describe, analyze, and interpret aspects of social world. (Human, 2006:50) The questions, too, were open-ended. That is, during the interviews, the researcher posed a general question which was accompanied by related explanations or questions. First of all, the researcher made an appointment with the participant in his/her workplace to conduct a 20-60 minutes interview. We, then, developed a structured-questionnaire to measure our quantitative variables. We verified the content and face validity of our questionnaire through consultation with the respective experts. In testing the reliability of our variables, the researcher measured the Cronbach Alpha for the structural, environmental, and behavioral factors which were set at $0 / 81,0 / 79$, and $0 / 88$, respectively, and the internal correlation of our questions was measured as $0 / 84$. The initial questionnaire was distributed among 30 clients and then, the unsuitable items or those whose internal correlation was lower than other items or the total score were replaced with new items.

\subsection{Study Population, Sample, and Sampling Method}

Our study population consisted of two groups: the first group was composed of those clients of Imam Khomeini Relief Committee who have developed their own businesses between 2005-2009 and have reached an acceptable level of self-sufficiency based on the indicators of this organization. Records showed that during this period some 260 clients have managed to become self-sufficient. According to Morgan table, we sampled 152 clients through random sampling method. Our second group, on the other hand, was comprised of the experts and authorities of the employment and self-sufficiency sectors of Imam Khomeini Relief Committee. Adopting a purposeful sampling method, we selected 12 experts and interviewed them.

\section{Research Findings}

\subsection{Findings According to the Descriptive Data of Our Variables}

Table 1. Results of the descriptive data of the research variables

\begin{tabular}{lcccccc}
\hline Elements & N & Min & Max & Mean & SD & Variance \\
\hline Structural & 152 & 39 & 62 & $27 / 50$ & $12 / 5$ & $51 / 26$ \\
Environmental & 152 & 20 & 38 & $31 / 30$ & $45 / 4$ & $83 / 19$ \\
Behavioral & 152 & 30 & 51 & $8 / 40$ & $41 / 5$ & $3 / 29$ \\
Rate of success & 152 & 9 & 21 & $37 / 16$ & $58 / 2$ & $67 / 6$ \\
\hline
\end{tabular}

According to Table 1, the structural element comprises a portion of the total squares. As it is shown above, $\mathrm{F}=$ $13 / 53$, and critical values for $\alpha=0 / 5$ and $\alpha=0 / 1$ were measured at $2 / 27$ and $3 / 14$, respectively, and the measured $F$ is higher that these two critical values. Consequently, the structural element can be a powerful predictor for the success rate of the self-sufficiency and self-employment plans of Imam Khomeini Relief Committee. Sig. $\leq 0 / 5$. 


\subsection{Regression Summary for the Structural Element}

Table 2. The results of regression for the structural variable

\begin{tabular}{ccccccccc}
\hline $\begin{array}{c}\text { Source of } \\
\text { variance }\end{array}$ & Total squares & DF & $\begin{array}{c}\text { Mean } \\
\text { squares }\end{array}$ & F & Sig & R & $\mathbf{R}^{2}$ & S. F \\
\hline Regression & $319 / 148$ & 5 & $63 / 83$ & $13 / 536$ & $0 / 000$ & $0 / 563$ & $0 / 317$ & $2 / 171$ \\
Remainder & $688 / 477$ & 146 & $4 / 716$ & & & & & \\
Total & $1007 / 625$ & 151 & & & & & & \\
\hline
\end{tabular}

5.3 The Significance of the Regression Model for the Structural Elements

Table 3. Significance of regression for the structural elements

\begin{tabular}{lccccc}
\hline Items & $\begin{array}{c}\text { Unstandard } \\
\text { ized Beta }\end{array}$ & SE & Beta & T & Sig \\
\hline Constant & $5 / 907$ & $1 / 863$ & & $3 / 171$ & $0 / 002$ \\
Space/Building & $-0 / 048$ & $0 / 107$ & $-\% 33$ & $-0 / 448$ & $0 / 655$ \\
Support/Capital & $0 / 299$ & $0 / 125$ & $0 / 185$ & $2 / 387$ & $018 / 0$ \\
Communication & $0 / 211$ & $0 / 147$ & $0 / 111$ & $1 / 443$ & $0 / 151$ \\
System & $0 / 554$ & $0 / 114$ & $0 / 413$ & $4 / 867$ & $0 / 000$ \\
Employment & $0 / 17$ & $0 / 121$ & $0 / 010$ & $0 / 142$ & $0 / 887$ \\
$\begin{array}{l}\text { Administrative } \\
\text { relations }\end{array}$ & & & & & \\
\hline
\end{tabular}

Among the five structural items, Beta coefficients are significant for support/capital and employment. Beta coefficients for capital and employment were measured at $0 / 185$ and 0/413, respectively, which assumes a significant role for these two items. The significance of these two items is also lower than $0 / 5$, and they just can be regarded as the relatively powerful predictors of the structural element. The correlation coefficient of the structural element, as the predictor variable, was $R=0 / 56$ and $R^{2}=0 / 317$; that is, the structural element can predict $0 / 317$ of the variance of our dependent variable.

Table 4. Results of regression analysis

\begin{tabular}{lcllllllc}
\hline $\begin{array}{l}\text { Source of } \\
\text { variance }\end{array}$ & Total squares & DF & $\begin{array}{l}\text { Mean } \\
\text { squares }\end{array}$ & F & Sig & & R $^{2}$ & S. F \\
\hline Regression & $1818 / 914$ & 3 & $606 / 305$ & $34 / 436$ & $0 / 000$ & $0 / 641$ & $0 / 411$ & $4 / 196$ \\
Remainder & $2605 / 764$ & 148 & $17 / 607$ & & & & & \\
Total & $4424 / 678$ & 151 & & & & & & \\
\hline
\end{tabular}

\subsection{Regression Summary for the Environmental Element}

As it is observed in Table 4, the correlation coefficient of the environmental element is measured for $\mathrm{R}$ and $\mathrm{R}^{2}$ at $0 / 64$ and $0 / 41$, respectively. That is, the environmental element can predict $0 / 41$ of the total variance of our dependent variable, which is a high coefficient. $F=34 / 43$ which is also higher than $2 / 67$ and $2 / 91$, so the environmental element is significant in the regression of $\frac{w}{z}$. 


\subsection{The Significance of the Regression Model for the Environmental Elements}

Table 5. The significance of the regression model for the environmental elements

\begin{tabular}{cccccc}
\hline Items & $\begin{array}{c}\text { Unstandardized } \\
\text { Beta }\end{array}$ & SE & Beta & T & Sig \\
\hline Constant & $15 / 830$ & $2 / 0519$ & & $6 / 284$ & $0 / 000$ \\
Supporters & $0 / 21$ & $0 / 180$ & $0 / 008$ & $0 / 116$ & $0 / 908$ \\
Incentives & $1 / 559$ & $0 / 227$ & $0 / 514$ & $6 / 875$ & $0 / 000$ \\
Rules and & $0 / 541$ & $0 / 222$ & $0 / 194$ & $2 / 433$ & $0 / 016$ \\
Regulations & & & & \\
\hline
\end{tabular}

According to Table 5, the items of incentives and regulations are significant at $\beta=0 / 514$ and $0 / 194$, and their significance is lower than $0 / 5$.

5.6 Regression Summary for the Behavioral Element

Table 6. Regression summary for the behavioral element

\begin{tabular}{lcccccccc}
\hline $\begin{array}{l}\text { Source of } \\
\text { variance }\end{array}$ & Total squares & DF & $\begin{array}{c}\text { Mean } \\
\text { squares }\end{array}$ & F & Sig & R & $\mathbf{R}^{2}$ & S. F \\
\hline Regression & $344 / 508$ & 6 & $57 / 41$ & $12 / 555$ & $0 / 000$ & $0 / 585$ & $0 / 342$ & $2 / 128$ \\
Remainder & $663 / 117$ & 145 & $4 / 573$ & & & & & \\
Total & $1007 / 625$ & 151 & & & & & & \\
\hline
\end{tabular}

As it can be observed above, $\mathrm{R}=0 / 585$ and $\mathrm{R}^{2}=0 / 34$, that is, the behavioral element has predicted $0 / 34$ of the variance of the dependent variable. $F=112 / 55$ which is higher than the two critical values of 2/6 and 2/92 for $\alpha=0 / 5$ and $\alpha=0 / 1$, respectively.

5.7 The Significance of the Regression Model for the Behavioral Elements

Table 7. The significance of the regression model for the behavioral elements

\begin{tabular}{lccccc}
\hline Items & $\begin{array}{c}\text { Unstandardized } \\
\text { Beta }\end{array}$ & SE & Beta & T & Sig \\
\hline Constant & $10 / 677$ & $1 / 636$ & & $6 / 528$ & $0 / 000$ \\
Innovation & $0 / 474$ & $0 / 110$ & $0 / 428$ & $4 / 295$ & $0 / 000$ \\
Creativity & $0 / 664$ & $0 / 144$ & $0 / 396$ & $4 / 615$ & $0 / 000$ \\
Leadership & $0 / 010$ & $0 / 154$ & $0 / 005$ & $0 / 067$ & $0 / 946$ \\
Training & $0 / 006$ & $0 / 106$ & $0 / 004$ & $0 / 055$ & $0 / 957$ \\
Risk & $-0 / 314$ & $0 / 191$ & $-0 / 119$ & $-1 / 643$ & $0 / 103$ \\
Opportunity & $1 / 817$ & $0 / 241$ & $0 / 611$ & $7 / 534$ & $0 / 000$ \\
\hline
\end{tabular}


The coefficients of the items of innovation, creativity, and opportunity are $0 / 428,0 / 396$, and $0 / 611$, respectively. Their significance, therefore, was set at $0 / 1$. So, the significant items based on their $\beta$-coefficient were: opportunity $(\beta=0 / 611)$, innovation $(\beta=0 / 428)$, and creativity $(\beta=0 / 396)$. The path coefficient between the structural and behavioral elements was $0 / 54$ according to the path analysis of the relationship between them, and this coefficient indicates of a powerful relationship between these two items. To put it another way, the behavioral element informed the success rate either directly or indirectly through taking a mediatory role between the structural element and the rate of success.

\section{Major Findings and the Answers of Research Questions}

In response to the first question of this study that "If the structural factors influence the success rate of the self-sufficiency and self-employment plans of Imam Khomeini Relief Committee?", it was found that the correlation coefficient of our structural factors (as the predictive variable) with the success rate of self-sufficiency plans (the dependent variable) was set at 0/56; that is, our R2 was equal to 0/317. It suggests that the structural factors are capable of predicting $0 / 317$ of the variance of our dependent variable. Among the structural factors, therefore, capital and employment were found to be more powerful in predicting the success rate of the self-sufficiency plans, and this finding is consistent with the work of Persson and Guido (2006). These authors have explored the contributions that the economic factors (capital, employment, and space, to name a few) make to and their direct relationships with entrepreneurship and the entrepreneurs.

As to our study's second question that "If the behavioral factors influence the success rate of the self-sufficiency and self-employment plans of Imam Khomeini Relief Committee?" the following answer was reached. It was found that the correlation coefficient of our behavioral factors (as the predictive variable) with the success rate of self-sufficiency plans (the dependent variable) was set at 0/585; that is, our R2 was equal to $0 / 34$. It suggests that the behavioral factors are capable of predicting $0 / 34$ of the variance of our dependent variable. Among the behavioral factors, therefore, innovation, creativity, and opportunity-seeking were found as meaningful. This finding corresponds with that of the work of Rauch and Michael (2002) who have studied the role of psychological factors and approaches in explaining the success of self-sufficiency plans. They observed that factors such as risk-taking, innovation, and creativity, independence, and education have a direct influence of entrepreneurship. On the other hand, Rothwell(1992) who has explored the role of innovation and creativity in entrepreneurship, argues that any entrepreneur requires a certain amount of creativity and innovation to be successful. Kirzner (1999) has emphasized on the role of creativity and risk-taking in explaining the achievement of self-sufficiency plans.

This study, then, answers the third question "If the underlying (environmental) factors influence the success rate of the self-sufficiency and self-employment plans of Imam Khomeini Relief Committee?, as following: it was revealed that the correlation coefficient of our environmental factors (as the predictive variable) with the success rate of self-sufficiency plans (the dependent variable) was set at $0 / 64$; that is, our R2 was equal to $0 / 41$. It suggests that the structural factors are capable of predicting $0 / 41$ of the variance of our dependent variable. Among the environmental factors, the incentives and regulations appeared more powerful in predicting the rate of success. Robson and Colin (2002) have identified the role of decreased, discounted tax and different insurances as incentives for entrepreneurship. Gilly(2002) and Gullen et al(2002) have examined the contributions of the socio-economic incentives and the external supporters to the development of self-sufficiency and self-employment plans.

And finally, the fourth question "To what extent does each one of the above-mentioned factors contribute to the success rate of the self-sufficiency and self-employment plans of Imam Khomeini Relief Committee?" was answered in the following manner. The explanation coefficient of the structural factors with the dependent variable was set at $0 / 317$; differently put, the structural factors were capable of predicting $0 / 32$ of the variance of our dependent variable. The explanation coefficient of the environmental factors with the dependent variable was set at $0 / 41$; that is, $0 / 41$ of our dependent was predicted by the environmental factors. And, $0 / 34$ of the variance of our dependent variable was decided to be predicted by the behavioral factors. If these three coefficients are added together, the result will be a bit more than 100 per cent, and it is due to the internal correlation of our factors and in the humanities, on the other hand, the independent variables are not separate from each other, rather they are interwoven. 


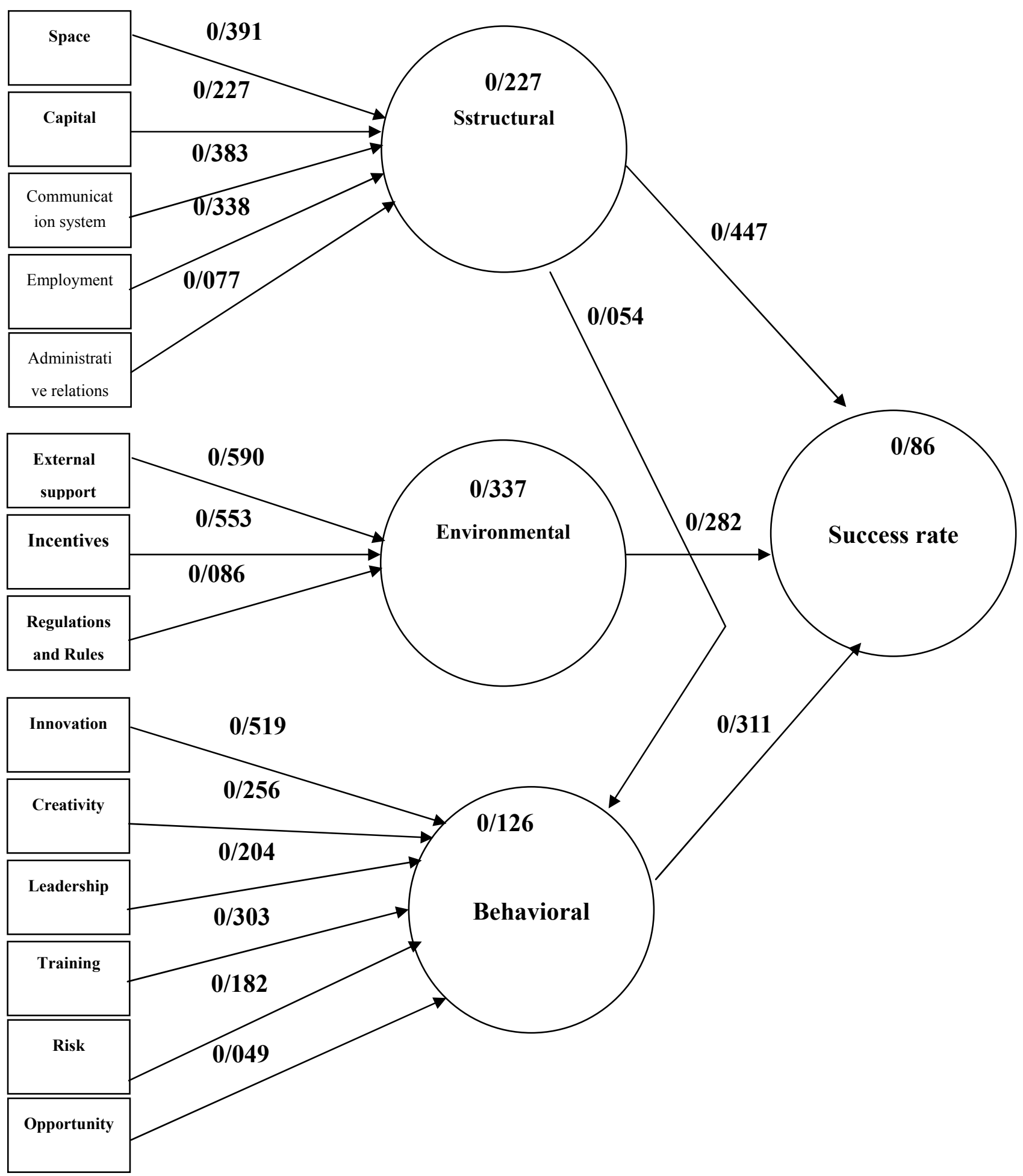

Figure 3. The path analysis and those variables which contribute to the success rate of the self-sufficiency and self-employment plans

\section{Research Limitations and Implications}

Based on the insights the current study provided, the proposing the following recommendations can be of a great importance in promoting the efficiency of self-sufficiency and self-employment plans ran by Imam Khomeini Relief Committee. 
- Imam Khomeini Relief Committee may develop a special bank with the mission of supporting the self-sufficiency and self-employment initiatives;

- Recruiting some occupation consultants in Imam Khomeini Relief Committee to direct the clients in the path of developing the self-sufficiency and self-employment initiatives;

- Transferring the development of the self-sufficiency and self-employment initiatives to the non-affiliated entrepreneurs while obliging them to make use of the competent clients of this organization;

- Making effective relationships with the social, cultural, and economic entities which can facilitate the process of launching the self-sufficiency and self-employment initiatives;

- Promoting self-confidence and motivation among the clients through advertising the exemplary businesses;

- Providing low-interest or interest-free loans may develop stable and efficient businesses;

- Our findings indicated that the experts laid a considerable emphasis on the meaningfulness of training, but it has not been demonstrated among our clients. Paying more attention to training, methods, competences of the trainers, motivation, and education level can make a difference;

- In developing their businesses, the clients, however, scarcely regard effective communication system, and it can be linked to their low education levels. Therefore, arranging special training courses could contribute to increasing their communication skills;

- Holding regular forums and festivals to exhibit the services and products of the client-led initiatives can be a good source of motivation for other peers;

- As the self-sufficient clients have some inherent entrepreneurial characteristics, the authorities are suggested to identify such individuals who have managed to make job for others and make grounds for their services to develop;

- With regard to the high demands of the market and the considerable achievements made by the clients of Imam Khomeini Relief Committee in the realm of entrepreneurship, it is suggested to establish homogenous clusters of business among the clients of this organization; and

- Cultivating the tradition of social entrepreneurship among the clients of this committee through publicizing the experiences and achievements of the exemplary clients in terms of business.

\section{References}

Alimiri, Mostafa. (2006). Social entrepreneurship: a review over the political and social backgrounds. The Quarterly of Management Knowledge, 19(72), 3-22.

Cullen, Julie Berry, and Robert H. Gordon. (2002). Taxes and Entrepreneurial Activity: Theory and Evidence from the US. NBER Working Paper No. 9015.

Gilley, Bruce, \& Thomas B. Gold Victoria E. (2002). Entrepreneurs and Politics in Rural China. In Bonnell, (Ed.), The New Entrepreneurs of Europe and Asia. New York and London: M.E. Sharpe.

Gregory, Diss. (2007). Are the humanitarians able to write the story of poverty? Retrieved from www.jobportal.ir

Human, Ali Heydar. (2006). A practical guide for qualitative research. Tehran: SAMT Publications.

Imam Khomeini Relief Committee. (2008). The Statistical Yearbook of 2007. Tehran: The Deputy for Planning and Parliamentary Affairs of the General Bureau of Planning and Information Technology.

Johnson, P. S., Parker, S. C., \& Wijbenga, F. (2006). Nascent entrepreneurship research: Achievements and opportunities. Small Business Economics, 27(1), 1-4.

Karnama, Asadollah. (2003). The study of the effective factors in self-sufficiency and self-employment of the Imam Khomeini Relief Committee of Kerman province. M.A. dissertation. Kerman Azad University.

Kurdistan Imam Khomeini Relief Committee. (2008). The statistical yearbook of 2007. Tehran: The Deputy for Planning and Parliamentary Affairs of the General Bureau of Planning and Information Technology.

Leadbeater, C. (2002). Social \& Civic Entrepreneurship. Retrieved from http://www.can online.org.uk

Merson, J., and Twersky F. (1996). New Social Entrepreneurs: The Success, Challenge and lessons of non-profit enterprise creation. San Francisco: The Roberts Foundation.

Ministry of Labor and Social Security. (2007). The Encyclopedia of Entrepreneurship. Tehran, pp458-473. 
Moghimi, Seyed Mohammad. (2004). Entrepreneurship in the institutes of civil society. Tehran: Tehran University Publications. P.91.

Mohajeri, Ali Reza. (2008). Principals of research methods: a guide to writing student dissertations. Tehran: Chapar Press.

Mohajeri, Ali Reza. (2009). Social entrepreneurial activity. Tehran: The Foundation of Encyclopedia Writing of the Institute of Social Security. P. 937-945.

OmraniTabarestani, Zahra. (2009). M.A. dissertation: The University of AllameTabatabaee, Department of Management. Retrieved from http://www.irandoc.ac.ir

Persson, Torsten \& Guido Tabellini. (2006). Electoral Systems and Economic Policy. In Weingast, Barry R. and Donald A. Wittman (Eds.), Handbook of Political Economy. New York: Oxford University Press.

Poordaryani, Ahmad. (2000). Theories, definitions, and patterns of entrepreneurship. Tehran: Agah Press. P.10.

Rauch, Andreas \& Michael Frese. (2000). Psychological Approaches to Entrepreneurial Success. A General. Model and an Overview of Findings. In Cooper, Cary L. and Ivan T. Robertson (Eds.), International Review of Industrial and Organizational Psychology, Chichester: Wiley, 101-142.

Roger. Spear. (2006). Social entrepreneurship: a different del. International Journal of Social Economics, 33, 399-410.

Shaker A. Zahra, H. R, Nachiket Bhawe, Donald O. Neubum, \& James. C. (2008). Globalization of social Entrepreneurship opportunity. Strategic Entrepreneurship Journal, 117-131.

Trevis .Certo., \& Toyah. Miller. (2008). Social entrepreneurship: Key issues and concepts. Business Horizon, 51, $267-271$.

Weerawardena, Jay, Mort Gillian Sulivan, \& Carnegie kashonia. (2000). Social Enterpreneurship: Towards Conceptualisation. International journal of Nonprofit and Voluntary Sector Marketing, 8(1), 76-88.

Weerawardena, Jay., \& Gillian Sullivan Mort. (2006). Investigating social entrepreneurship: A multidimensional model. Journal of World Business, 41, 21-35. 